\title{
Short polarity intervals within the Matuyama: transitional field records from hydraulic piston cored sediments from the North Atlantic
}

\author{
Brad M. Clement ${ }^{1}$ and Dennis V. Kent ${ }^{2}$ \\ ${ }^{I}$ Ocean Drilling Program and Department of Geophysics, Texas A \& M University, College Station, TX 77843 (U.S.A.) \\ ${ }^{2}$ Lamont-Doherty Geological Observatory and Department of Geological Sciences, Columbia University, Palisades, NY 10964 (U.S.A.)
}

Received May 28, 1986; revised version received October 17, 1986

\begin{abstract}
Detailed sampling of two short magnetozones within the Matuyama Chronozone recorded at DSDP Site 609 $\left(49.86^{\circ} \mathrm{N}, 335.77^{\circ} \mathrm{E}\right)$ confirms that one, the Cobb Mountain Subchronozone (1.12 Ma), is a very short, full normal polarity interval and that the other, the older interval, is a record of a geomagnetic excursion which occurred at approximately 1.55 Ma. The Cobb Mountain Subchron lasted approximately 25,000 years, one third the duration of the Jaramillo Subchron. The normal polarity interval is bounded by two transition zones which document an antisymmetry in the sequence of directions in the reverse to normal and normal to reverse polarity transitions. We interpret the antisymmetry as reflecting a dependence upon the sense of the reversal, without significant changes in the relative contributions of non-dipole terms. The polarity interval recorded at $1.55 \mathrm{Ma}$ lasted only 8,800 years with what may be regarded as full polarity directions observed across only $3 \mathrm{~cm}$ of stratigraphic section. This feature is interpreted as an excursion of the geomagnetic field and appears to be correlative with the Gilsa Subchron. Similarities between the transition bounding these two magnetozones suggest that these features occur as the result of the same process or triggering mechanisms in the earth's outer core.
\end{abstract}

\section{Introduction}

Short geomagnetic polarity features ranging from excursions to full polarity intervals have frequently been reported, but only rarely have their occurrences and ages been well documented [1]. Excursions and short polarity intervals are brief but large departures of the geomagnetic field from its time averaged state. During excursions, large field changes are followed by a return to the original polarity while a short polarity interval comprises a reversal to full, opposite polarity directions followed shortly thereafter by a second reversal that returns the field to the original polarity. Both excursions and short polarity intervals (often referred to in the literature as short events) are of particular interest because they represent the shortest, large-scale field changes readily detectable in the paleomagnetic record. The details of field behavior during these intervals and the frequency at which they occur are poorly known, and therefore it is not clear how these geomagnetic features are related to the reversals that bound long polarity intervals. By closely examin- ing the timing and distinctive features of these intervals, we may be able to place them within the context of our understanding of polarity reversals and, in turn, learn more about the processes which cause reversals.

Little is known about the details of excursions or short polarity intervals because of the difficulty in obtaining reasonable paleomagnetic records of such short lived events. Pelagic sediments provide a potential source of paleomagnetic records of brief geomagnetic phenomena because of the relatively continuous (although slow) deposition rates. Detailed sampling of polarity reversals in pelagic sediments has successfully yielded high resolution transition records [2,3]. For this reason we decided to extend our study of polarity transitions to two short magnetozones recorded in North Atlantic sediments.

\section{Magnetostratigraphy}

Leg 94 of the Deep Sea Drilling Project (DSDP) drilled a transect of six sites in the North Atlantic Ocean in order to study the late Miocene to 
Recent paleoceanographic evolution of this basin [4]. At each of these sites the hydraulic piston corer (HPC) recovered undisturbed sediment cores from as deep as 150-200 meters beneath the seafloor (mbsf). These sediments proved to be very well suited for magnetostratigraphic study; the relatively constant but high (up to $80 \mathrm{~m} / \mathrm{m}$.y.) sedimentation rates and the stable remanent mag- netizations carried by these sediments provide a detailed record of geomagnetic polarity history for the last 3-4 m.y. [5].

In particular, the high sedimentation rates observed at Site 609 provide a very detailed polarity record. Fig. 1 shows the correlation of the major polarity zones observed at the three holes drilled at Site 609 with the geomagnetic polarity time

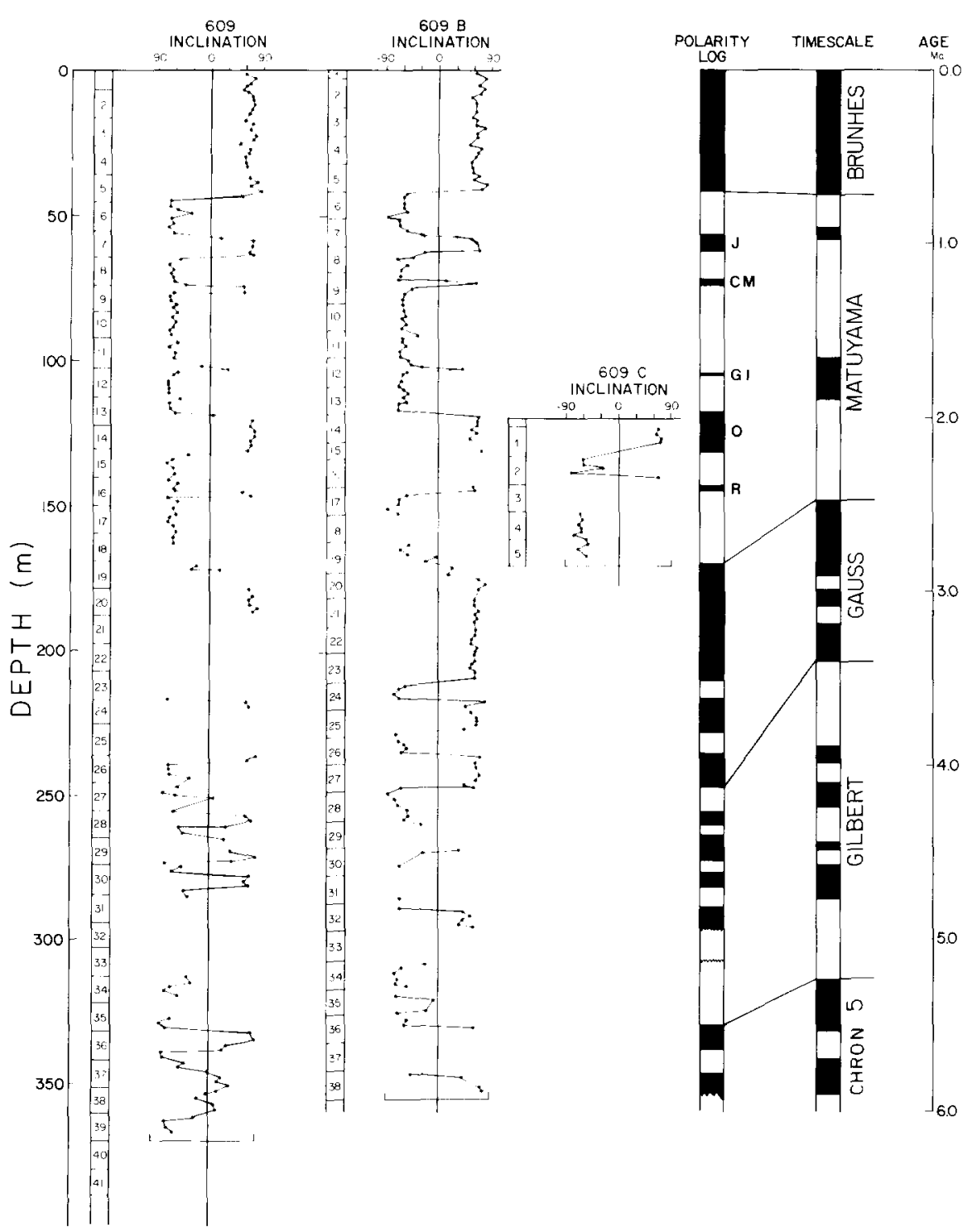

Fig. 1. Magnetostratigraphy of Site 609. Inclination records, obtained from discrete samples $\left(7 \mathrm{~cm}^{3}\right)$ after partial AF demagnetization at $10 \mathrm{mT}$, plotted versus sub-bottom depth. The inclination records are summarized in a composite polarity log which is correlated with the magnetic polarity timescale (MPTS). Note that the Cobb Mountain $(C M)$ and Gilsa ( $G I$ ) Subchronozones are detected in the discrete sample records from both Hole 609 and Hole $609 \mathrm{~B}$, while evidence for the Reunion $(R)$ is seen in Holes 609 , 609B and $609 \mathrm{C}$. The Jaramillo $(J)$ and Olduvai $(O)$ are typically observed within the Matuyama Chron. 
scale [6]. Because the cores were not azimuthally oriented, the inclination records alone were used to interpret the polarity. Gaps in the record were filled by coring three holes at this site, each laterally offset several tens of meters. Intervals of low recovery or disturbed sediment in one hole were recovered in one of the offset holes. This method produced a nearly complete composite section through the base of the Gauss Chronozone.

In addition to the major polarity chronozones, three very short magnetozones are observed in these records from Site 609 . One occurs $10 \mathrm{~m}$ below the base of the Olduvai, a second occurs 15 $\mathrm{m}$ above the top of the Olduvai and a third occurs $10 \mathrm{~m}$ below the base of the Jaramillo Subchronozone. The short magnetozones observed at Site 609 just below the Jaramillo and Olduvai Subchronozones occur at several of the sites drilled during Leg 94 and in multiple holes at some sites.

Age estimates of these magnetozones (made on the basis of sedimentation rates as discussed below) suggest that two of them may be correlative with short polarity chrons previously reported from both sediments and igneous units. The normal polarity zone $10 \mathrm{~m}$ beneath the Olduvai (which we were unable to sample in detail) estimated at 2.02 $\mathrm{Ma}$, is correlated with the Reunion Subchron $[7,8]$.

The short normal polarity zone observed at 74 mbsf (just older than the Jaramillo Subchron) at Site 609 appears to be correlative with the Cobb Mountain Subchron. Mankinen et al. [9] reported a normal polarity magnetization from lavas which yielded a potassium-argon age of $1.12 \mathrm{Ma}$. Other occurrences of a normal polarity zone just older than the Jaramillo Subchron have been reported from deep-sea cores from the Pacific Ocean [10-12] and more recently from hydraulic piston cores in the East Pacific, Caribbean and North Atlantic $[13,14]$. The existence of this subchron is also supported by stacked marine magnetic anomaly profiles [15]. The presence of a short normal polarity zone at depths corresponding to ages of 1.1-1.2 $\mathrm{Ma}$ in cores from five of the six sites drilled on Leg 94 supports the existence of an interval of normal polarity just older than the Jaramillo Chron.

The very short polarity subchronozone located just above the Olduvai Subchronozone, with an estimated age of $1.55 \mathrm{Ma}$, is present in two holes drilled at Site 609 verifying that it is not simply a sampling artifact. Although other investigations of sedimentary sections spanning this time interval have reported the possibility of additional normal polarity intervals younger than the Olduvai $[16,17]$, correlation of the zone observed at Site 609 with any of these is not certain.

The interpolated age of $1.55 \mathrm{Ma}$ is in close agreement with the $\mathrm{K} / \mathrm{Ar}$ date of $1.58 \pm 0.02$ from a normal polarity lava in East Iceland $[8,18]$. Significant debate arose as to whether this lava had recorded a separate normal polarity subchron, called the Gilsa, that is significantly younger than the Olduvai Subchron. Watkins et al. [18] conducted a detailed study of the section where the Gilsa Subchronozone was originally reported and reported a normal polarity lava yielding an age of $1.58 \pm 0.02 \mathrm{Ma}$ overlying a normal polarity lava with an age of $1.67 \pm 0.06$. The older age falls well within the limits of the Olduvai Subchron, while the younger age is significantly younger than the Olduvai. The evidence from the lavas (and their radiometric dates) alone did not supply enough evidence to warrant distinguishing two separate subchrons $[8,19]$.

The data presented here, from DSDP Site 609, provides strong stratigraphic evidence that a separate, very short, normal polarity interval or excursion is recorded 15 meters above the top of the Olduvai. We interpret this magnetozone as a record of the Gilsa Subchron.

\section{Methods}

We sampled two of the short magnetozones recorded at DSDP Site 609, the Cobb Mountain (CM; Fig. 1) and the Gilsa (GI; Fig. 1), by taking U-channel samples spanning the polarity intervals as defined by the standard size discrete sample (nominally $7 \mathrm{~cm}^{3}$ cubes) measurements. Passthrough magnetic susceptibility measurements were made on the U-channel samples prior to sub-sampling using a $70 \mathrm{~mm}$ diameter sensor loop and a Bartington susceptibility meter in order to monitor possible gross changes in the magnetic carriers in these sediments.

The U-channel samples were then continuously sub-sampled by slicing $0.5 \mathrm{~cm}$ thick samples of the wet sediment using a stainless steel wire. The slices were placed in plastic boxes in a known orientation and then measured using a cryogenic 
magnetometer. We progressively demagnetized at least one sample per $5 \mathrm{~cm}$ of stratigraphic section at increments ranging from 5 to 10 millitesla (mT) up to a maximum of $80 \mathrm{mT}$, using a single axis alternating field demagnetizer. The results (Fig. 2A) agree with progressive demagnetization of both standard size paleomagnetic samples and other U-channel specimens from polarity transition zones from Site 609 [5,20]. In many cases, a steep, downwardly directed component is removed by treatment at AF levels up to $10 \mathrm{mT}$, isolating a component which decays univectorially with treatment at progressively higher fields. Specimens exhibiting transitional directions show the same response to progressive demagnetization (Fig. 2B, C), indicating that the intermediate directions are not the products of unresolved multicomponent magnetizations. On the basis of these results we interpret the directions observed after treatment at $20 \mathrm{mT}$ as records of geomagnetic field behavior near the time of deposition of these sediments.

\section{Cobb Mountain}

The $3 \mathrm{~m}$ of successive U-channel samples spanning the Cobb Mountain in Hole 609B yielded more than 570 discrete specimens for measurement. The results after partial AF demagnetization at $20 \mathrm{mT}$ are presented in Fig. 3. The normal polarity zone is identified by a $180^{\circ}$ change in directions from the full reverse polarity directions observed below $75.8 \mathrm{mbsf}$ and above $74.05 \mathrm{mbsf}$.

Within the full polarity zones the directions vary by as much as $40^{\circ}$ about a mean inclination in good agreement with that predicted by an axial dipole field $\left(67^{\circ}\right)$ for this site latitude. This variation occurs in gradual succession spanning 25-30 $\mathrm{cm}$ of section and exhibits good serial correlation. We interpret this variation as a record of secular variation. This suggests that these sediments are capable of recording the details of field behavior on similar time scales as expected for transitional field variations.

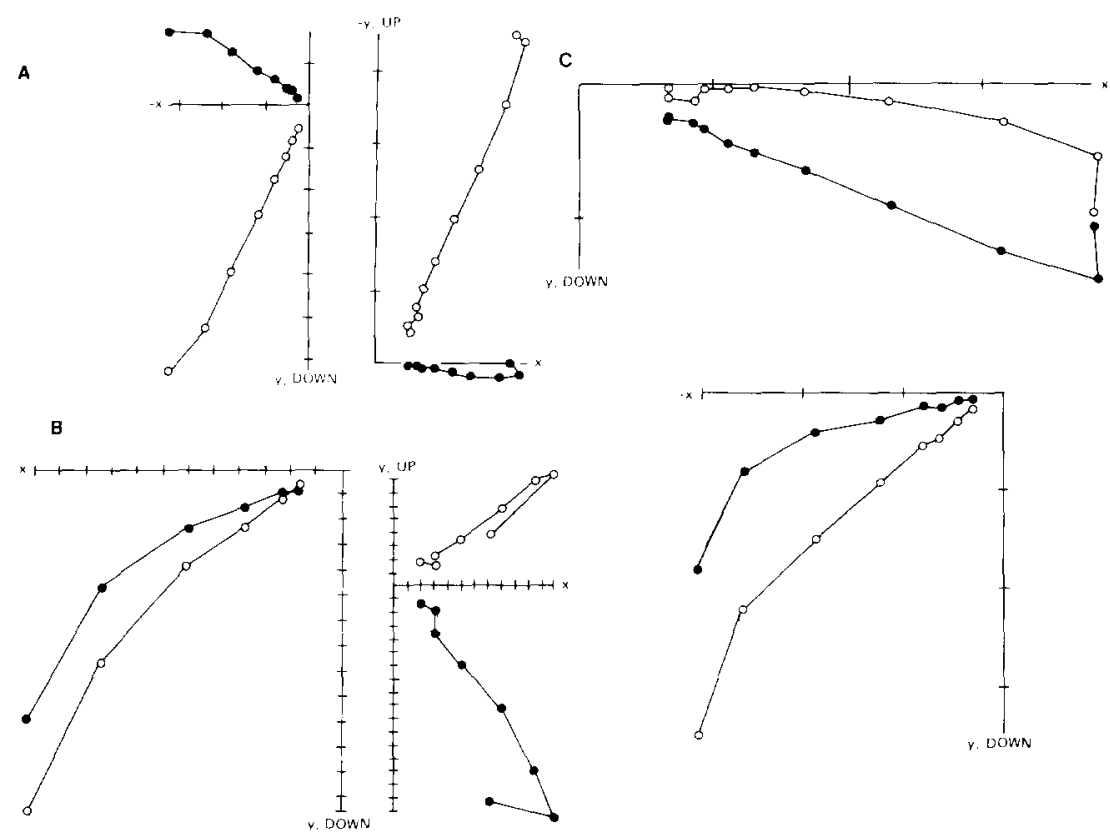

Fig. 2. Representative results of progressive AF demagnetization of the natural remanent magnetization. Open (solid) symbols representing vector endpoint projections onto the vertical (horizontal) plane. A. Results from two full polarity specimens from immediately above and beneath the Cobb Mountain Subchronozone. Tick marks are spaced at intervals corresponding to $1 \times 10^{-3}$ A $/ \mathrm{m}$. B. Two specimens from the Cobb Mountain Subchronozone which yield intermediate directions. Tick marks are spaced at intervals corresponding to $1 \times 10^{-4} \mathrm{~A} / \mathrm{m}$. C. Two specimens from the Gilsa Subchronozone which yield intermediate directions. Tick marks are spaced at increments corresponding to $5 \times 10^{-4} \mathrm{~A} / \mathrm{m}$. 


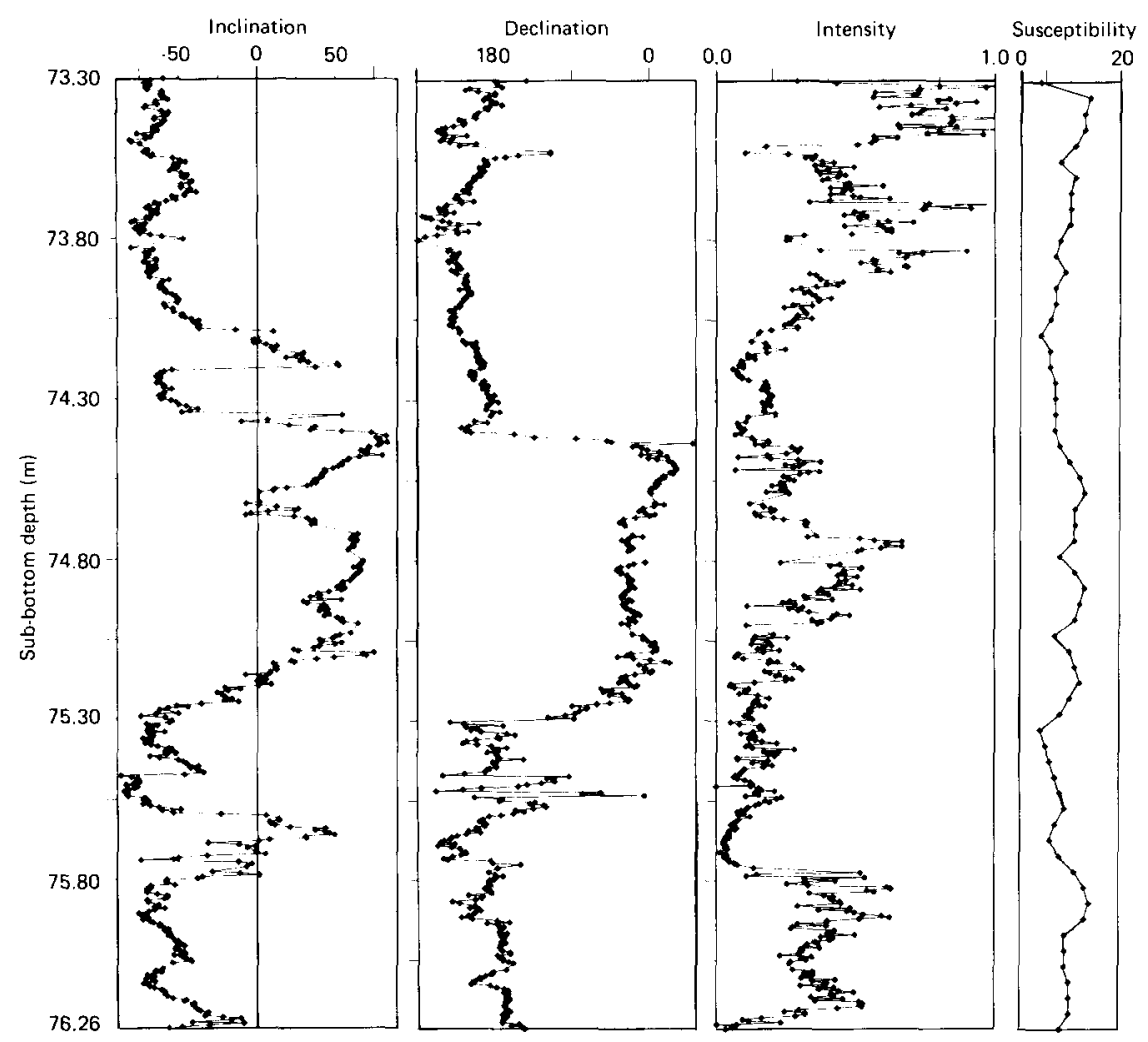

Fig. 3. Paleomagnetic results of discrete sample measurements from the Cobb Mountain Subchronozone after partial AF demagnetization at $20 \mathrm{mT}$ plotted as inclination, declination, NRM intensity (in units of $10^{-2} \mathrm{~A} / \mathrm{m}$ ) and susceptibility (in units of $4 \pi \times 10^{-3} \mathrm{SI}$ ) versus sub-bottom depth.

The polarity transitions bounding the normal polarity interval do not consist of simple $180^{\circ}$ progressions from full polarity directions to those of the opposite polarity. Instead, a definite structure exists in the transition zones. In the deeper, reverse to normal transition, the inclination shallow, passing through the horizontal but then return to nearly full reverse polarity directions before finally moving to full normal polarity directions. Within the nominally full normal polarity interval, the inclinations shallow to directions very close to the horizontal and then recover to full normal polarity directions while the declinations maintain nearly constant, normal polarity values, $180^{\circ}$ out from reverse polarity directions. This excursion is difficult to separate from the normal to reverse polarity transition which terminates the Cobb Mountain in which the same sequence seen in the reverse to normal transition occurs, only in the opposite order: The inclinations move toward steep negative values, then rapidly recover to steep positive values before finally settling in to reverse polarity directions by $74.05 \mathrm{mbsf}$.

The nearly $180^{\circ}$ changes in declination values roughly bound the stratigraphic range of full normal polarity inclinations. Much of the complexity observed in the declination record coincides with very steep directions and does not reflect a corresponding degree of dispersion in the total vector directions.

The normal polarity interval is bounded by two lows in magnetization intensity which coincide with the transitions between the normal and reverse polarity zones. Within the normal polarity interval the intensities recover, reaching values observed in the full polarity intervals above and below the Cobb Mountain Subchronozone. Although there is considerable scatter in the intensity data, the record is characterized by a gradual progression to values roughly $5-10 \%(0.03 \times$ 
$10^{-2} \mathrm{~A} / \mathrm{m}$ ) of the mean values observed in the full polarity intervals $\left(5.0 \times 10^{-2} \mathrm{~A} / \mathrm{m}\right)$. This same range of variation is not observed in the pass-through susceptibility measurements (Fig. 3). The lack of covariance suggests that the observed intensity variations are not likely to be a result of downcore variations in the nature or amount of magnetic material, but instead may be interpreted as records of relative changes in the ambient magnetic field near the time of deposition [21,22].

The virtual geomagnetic pole (VGP) path calculated for the Cobb Mountain polarity interval is shown in Fig. 4. The path has been divided into five segments in order to present the data more clearly. The VGPs first circle in a broad counter-clockwise loop to latitudes as low as $6^{\circ}$ (Fig. 4A). They then steadily progress in a far-sided path to high latitudes (Fig. 4B). Fig. 4C shows the VGPs observed during the full polarity interval, including the deviation to shallow directions at $230-235 \mathrm{~cm}$. Part of this same interval is replotted in Fig. 4D along with the near-sided path from normal to reverse polarity VGPs. And, finally, the VGPs swing in a clockwise loop to very low latitudes before clustering at high southern latitudes (Fig. 4E).

\section{Gilsa Subchronozone}

The record of the Gilsa Subchronozone is defined by 270 samples spanning $1.5 \mathrm{~m}$ of section (Fig. 5). Unlike the Cobb Mountain Subchronozone, the Gilsa does not exhibit a sustained interval of normal polarity directions. In fact, close to normal polarity directions are only observed across $3 \mathrm{~cm}$ of core. Although the inclinations reach steep, positive values, they fluctuate back to shallow and then back to steep positive

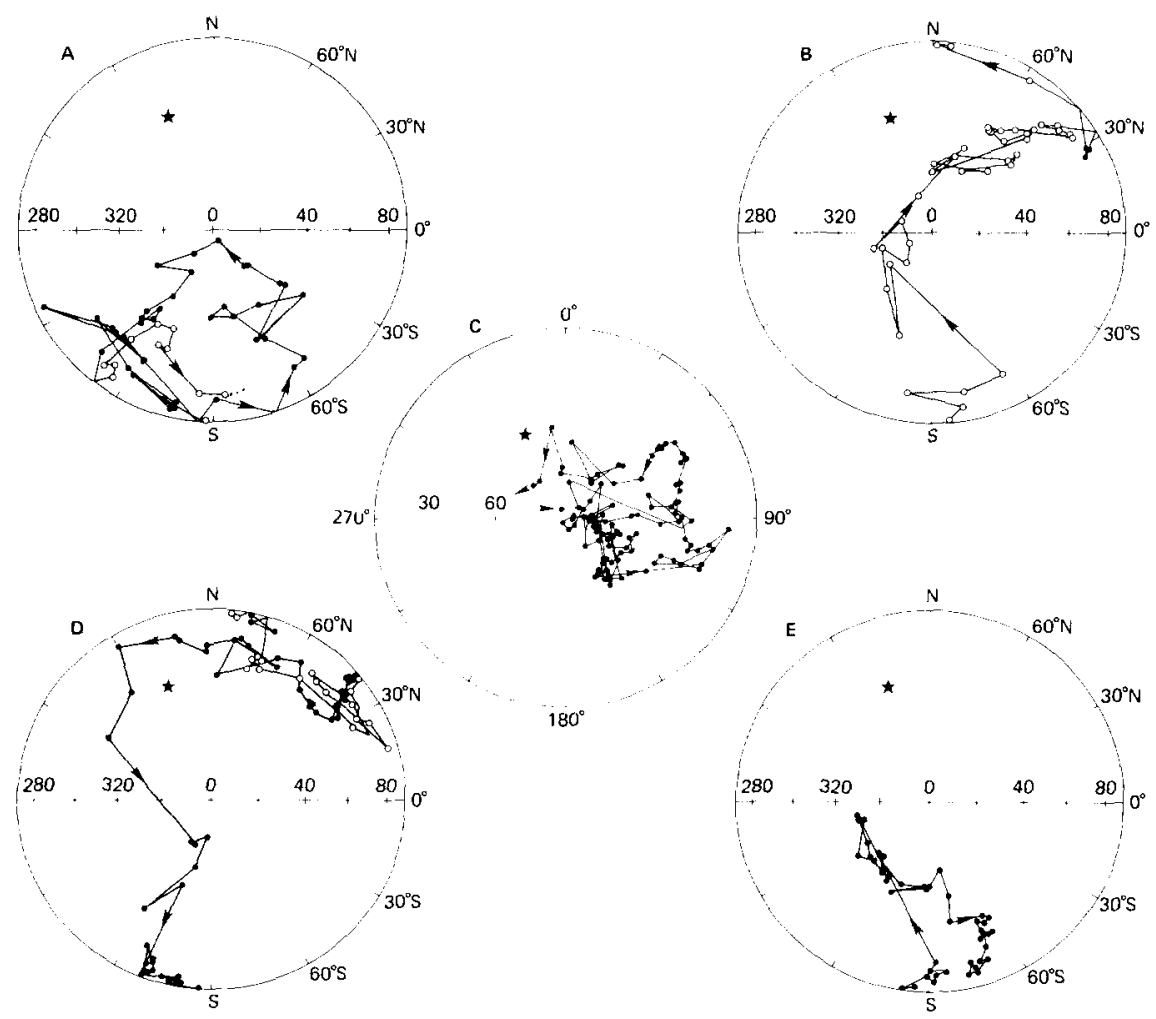

Fig. 4. Virtual geomagnetic pole (VGP) path for Cobb Mountain Subchronozone. The VGP's were calculated by making a uniform correction for the declination data to bring the unoriented core results into agreement with the polarity interpretations based on the inclination data. The VGP path is separated into five contiguous segments for ease of illustration; segments are discussed in the text. Paths are plotted on equal area stereographic projections. Open (closed) symbols represent projection onto upper (lower) hemisphere. Star indicates location of DSDP Site 609. 


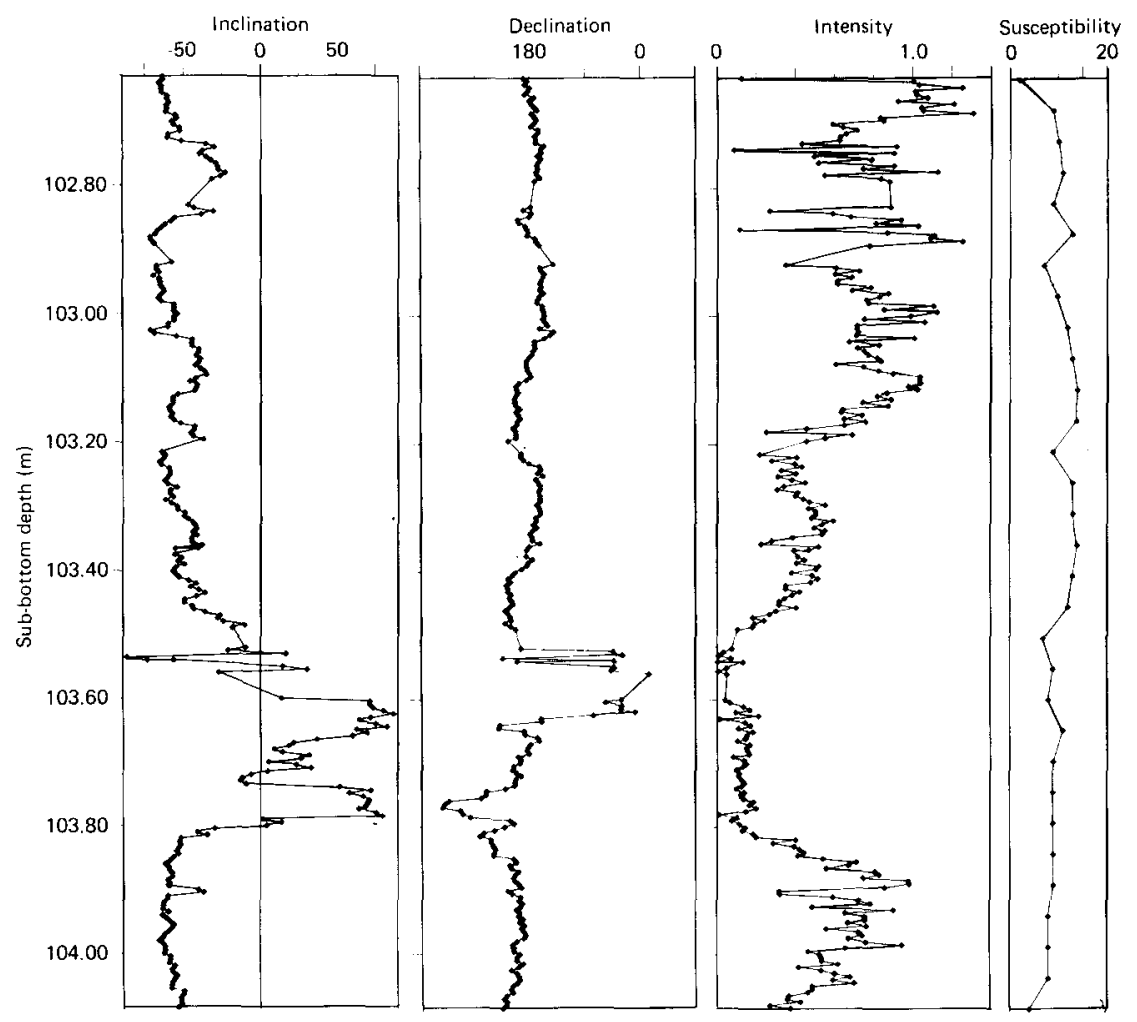

Fig. 5. Paleomagnetic results of discrete sample measurements from the Gilsa Subchronozone after partial AF demagnetization at 20 $\mathrm{mT}$ plotted as inclination, declination, NRM intensity (in units of $10^{-2} \mathrm{~A} / \mathrm{m}$ ), and susceptibility (in units of $4 \pi \times 10^{-3} \mathrm{SI}$ ) versus sub-bottom depth.

directions before returning to negative values. The declinations do not exhibit a $180^{\circ}$ shift in direct correspondence with the inclination change. In- stead, the declinations move to normal polarity directions only at the very end of the inclination variation. The end result is that, although the total

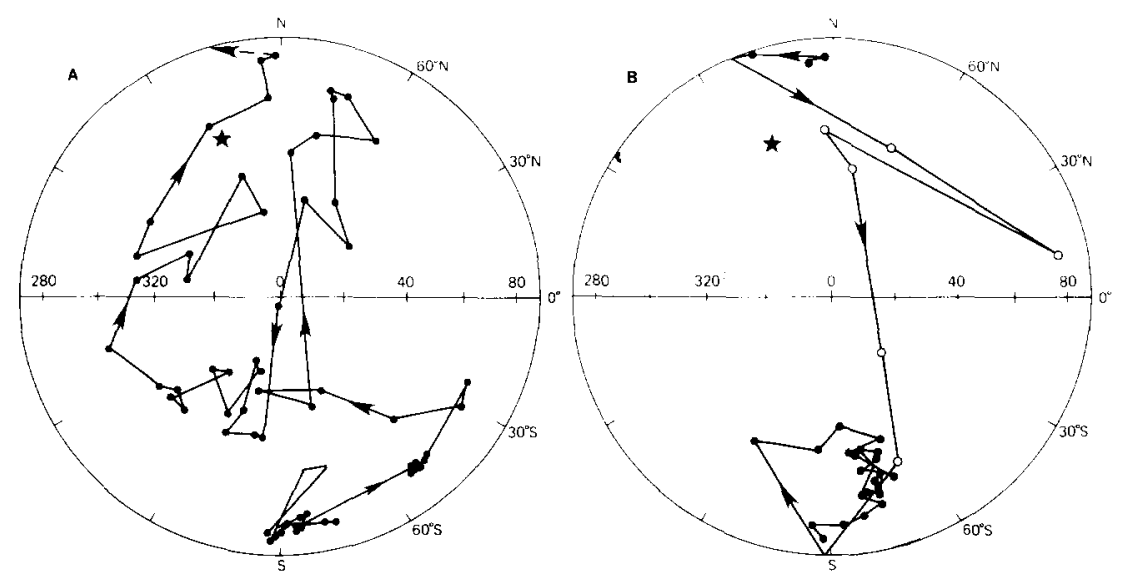

Fig. 6. VGP path (presented in two contiguous segments for ease of illustration) calculated for the Gilsa Excursion. See caption to Fig. 4 for explanation. 
vector moves more than $170^{\circ}$ away from the reverse polarity direction, it never stabilizes near normal polarity values.

The entire directional change occurs within an intensity low (which again, is not accompanied by a corresponding variation in magnetic mineralogy as recorded by the susceptibility measurements). The intensities drop to $15 \%$ of those observed above and below the event. No change occurs in the directions until the intensities have reached the minimum. Likewise, the intensities do not begin to increase again until the directions have settled about the full reverse polarity directions.

The VGP path calculated for this interval (Fig. 6) exhibits a complicated near-sided path toward normal polarity, with a progression to high northern latitudes, followed by a retreat to middle southern latitudes before moving to very high $\left(83^{\circ}\right)$ northern latitudes (Fig. 6A). The VGPs then rapidly return to southern latitudes, again following a far-sided path, and finally settle about the south geographic pole after a small, clockwise loop (Fig. 6B).

\section{Durations}

The ages of the sediments cored on DSDP Leg 94 are well constrained by biostratigraphic and magnetostratigraphic data. The nannofossil and foram nannofossil oozes at Site 609 were deposited in a predominantly pelagic realm. Sedimentation rates over the uppermost $150 \mathrm{~m}$ of Hole 609B are based on best fit lines drawn through the age/depth data provided by the depths of the major polarity reversal boundaries. Sedimentation appears to be continuous and relatively constant although a change in slope in the accumulation rate curve just below the Jaramillo Subchronozone indicates a change in the sedimentation rate. The rates change from $54.5 \mathrm{~m} / \mathrm{m}$.y. from the sediment water interface (zero age) through the base of the Jaramillo, to $73.7 \mathrm{~m} / \mathrm{m} . \mathrm{y}$. from the base of the Jaramillo to the top of the Gauss.

The following age and duration estimates for the Cobb Mountain and Gilsa assume that sedimentation rates $(73.7 \mathrm{~m} / \mathrm{m}$.y.) remained constant across these intervals and that the depths of the major polarity reversal boundaries have not been offset as a result of coring disturbances. The correlation between reversal boundaries in the upper portions of Holes 609 and 609B suggest that these are not serious problems.

The midpoint of the Cobb Mountain Subchronozone occurs at $74.9 \mathrm{mbsf}$ which corresponds to an average age of $1.16 \mathrm{Ma}$. The age of $1.16 \mathrm{Ma}$ agrees well with the age of $1.12 \mathrm{Ma}$ derived from radiometric dating of normal polarity lavas observed at Cobb Mountain in the Clear Lakes Volcanic Field [9]. The total directional change associated with this polarity interval occurs from 74.05 to $75.805 \mathrm{mbsf}$, corresponding to 23,800 years with the interval of full normal polarity directions lasting about 11,600 years. The reverse to normal polarity transition took 8300 years while it took about 3900 years for the directions to move from normal to reverse polarity. The intensity variations associated with the entire Cobb Mountain directional changes span a thickness corresponding to 25,500 years.

The midpoint of the Gilsa Subchronozone occurs at 103.7 mbsf, corresponding to an age of 1.55 Ma. The directional change occurs from 103.575 to $103.815 \mathrm{mbsf}$ and apparently only lasted approximately 4600 years; the intensity variation lasted nearly twice that long, taking up to 8800 years.

\section{Interpretation}

Magnetostratigraphic study of the Site 609 cores identified polarity zones ranging from constant polarity intervals more than $40 \mathrm{~m}$ thick (e.g. the Brunhes Chronozone) down to intervals as short as a few centimeters thick (the Gilsa). Detailed sampling of two very short polarity intervals identified at Site 609 provide records which help us understand how these very short polarity events relate to longer polarity intervals and with long term geomagnetic field behavior.

The short normal polarity subchronozone located just beneath the Jaramillo Subchronozone is correlated with the Cobb Mountain Chron. The Cobb Mountain Subchronozone at Hole 609B is characterized by a full $180^{\circ}$ change in directions from mean reversed polarity values to normal polarity directions. The interval of normal polarity directions is bounded above and below by complex transition zones which exhibit good internal consistency as evidenced by the degree of serial correlation as the directions progress from reverse 
to normal polarity directions and then back again. Each of these polarity transitions occurs within a distinct minimum in magnetization intensities. Given the qualifications which must be made in interpreting relative geomagnetic field intensity variations from a sediment record it appears that the field intensity decreased and then recovered as the directions reached full polarity values.

The Cobb Mountain polarity transitions include large swings in inclinations which may be records of what previous workers have called oscillations, rebounds or partial recoveries of polarity. Based solely on the directional data it is difficult to define boundaries for the transition zones because of the oscillating nature of the inclination records. These features cannot be a product of burrowing of bottom dwelling organisms because a burrow would be expected to completely reset the magnetization $[23,24]$. As is clear from Fig. 3 the inclination changes are not necessarily accompanied by changes in the declinations.

Although these large directional swings resemble excursions of the geomagnetic field, their occurrence within the intensity minima and general proximity to the transition suggests that they are part of the transitional field behavior. This is consistent with behavior observed in the upper Olduvai polarity transition record reported at this same site [20]. The upper Olduvai polarity transition exhibits a dramatic partial polarity recovery that occurs within the transition zone as defined by the bounds of the intensity variation. Similar behavior has been reported from igneous rocks recording a Miocene reversal at Steen's Mountain [25,26]. Valet et al. [27] reinterpreted a portion of the Steen's Mountain transition as a separate geomagnetic event on the basis that the intensity increases between the transition and the excursion. The evidence from the Site 609 data indicates that partial rebounds of this type may be part of the transitional field behavior, supporting Mankinen et al.'s [25] original interpretation. If this is the case it means that the recent models which have been developed assuming a simple flux flooding mechanism [28] within the core may not be adequate to explain fully the behavior of the earth's magnetic field during a polarity transition.

The transition zones bounding the Cobb Mountain Subchronozone form a set of sequential transitions from the same site. Continuous sampling of the intervening interval between the two transition zones gives great confidence that these reversals are truly sequential. This allows a comparison of the two reversals without the added complications of site dependent variables or long term changes in the geomagnetic field between the two reversals. Differences in the transition records therefore may be more readily interpreted as differences in the nature of the geomagnetic field during each of these reversals. The structure in the transition zones, namely the partial recoveries in the inclination records, define an antisymmetry with respect to the sense of the reversal, from normal to reverse or reverse to normal polarity. In other words the same features are observed in both records but they occur in the opposite order. This is very similar to results observed comparing two reversal transitions from the southern hemisphere [3].

In the case of the southern hemisphere data, comparison of the upper Olduvai and lower Jaramillo transition zones revealed some striking similarities in features, such as very steep upward directions. The sequence of features however was opposite in the two reversals; the same events in the upper Olduvai occurred in the opposite time order as in the lower Jaramillo. Modeling of these transitions using a zonal harmonic model [29] showed that the antisymmetry in these two transitions could be explained as simply a function of the sense of the reversal. If the relative magnitudes of a non-dipole field remain constant while the dipole term is allowed to decay through zero and build up in the opposite direction, antisymmetric records are predicted. Thus the antisymmetry observed in both the two southern hemisphere records and the transitions bounding the Cobb Mountain Subchronozone may be interpreted as indicating that the transitional fields differed predominantly in the sense of reversal, from normal to reverse or from reverse to normal polarity, rather than in non-dipole field content.

The Gilsa Subchronozone comprises a change in the directional and intensity data which spans $65 \mathrm{~cm}$, lasting only 8800 years. Strictly speaking, this represents a very short normal polarity interval. The normal polarity directions, however, are only observed across $3 \mathrm{~cm}$ of stratigraphic section, corresponding to less than 500 years out of the 4600 year long directional variation. The entire directional change occurs within a low in the 
magnetization intensities, which together with the short duration of the normal polarity directions suggest that the geomagnetic field never fully recovered in the normal polarity state. This, along with the timing of this polarity subchronozone, makes it more similar to geomagnetic excursions than to short, full polarity intervals.

Coe et al. [30] and Hoffman [31] have reviewed the paleomagnetic evidence for several excursions reported in the literature. In many cases the excursions are defined by wide departures of the directions from full polarity directions accompanied by a dramatic decrease in intensities. The notable exception to this is the Lake Mungo Excursion $[32,33]$ which exhibits a pronounced increase in paleointensities associated with the excursion in directions. The Lake Mungo Excursion has been modeled using a local non-dipole source which is allowed to increase relative to the dipole field [34]. Similarly, the other excursion data suggest that the non-dipole components have dominated, but in these cases only because the dipole field has decreased substantiallly. The data presented here for the Gilsa agree with the majority of the excursion data from both lavas and sediments in that the directional change occurs within a distinct intensity minimum.

Coe et al. [30] also suggested that some of the excursions they looked at from Oahu, recorded in lava sequences, may be only partial records of full polarity intervals. It may be possible that other records are also incomplete, and that more of what are considered to be excursions may in fact have been very short intervals of full polarity. The high resolution, continuous records from Site 609 support this hypothesis because we find a few full polarity directions within a feature which otherwise resembles an excursion. In fact if the three centimeters of full polarity directions had not been sampled we would not have hesitated in calling this feature an excursion. On the other hand, detailed records such as the Mono Lake Excursion [35] indicate that excursions do exist as large directional deviations which never approach opposite polarity directions.

We are left with the conclusion that the Gilsa fails to fit neatly into the accepted categories of excursions or short polarity intervals. Instead, this feature appears to bridge the gap between these two end members and suggests that the geomag- netic field exhibits a complete spectrum of polarity behavior.

\section{Discussion}

The results presented here confirm that the Cobb Mountain Subchron (1.12 Ma) is a short (ca. 25,000 years), full normal polarity interval, whose bounding transition zones reveal an antisymmetry in back to back field reversals. The antisymmetry may be interpreted as being dependent largely on the sense of the polarity change with no need to vary the non-dipole contributions between the two.

The interpretation of the very short (ca. 8500 years) feature we correlate with the Gilsa Subchron is less clear. During this interval directions approach normal polarity directions (within $10^{\circ}$ ) and then rapidly return to reverse polarity directions. The few full normal polarity directions may represent a failed attempt of the dipole field to stabilize in the opposite polarity, and therefore the normal polarity directions may be a global feature. In order to consider the Gilsa as an aborted polarity interval, however, the dipole field must reverse twice within a very short period. It may be more reasonable therefore to regard the antipodal directions as a result of a fortuitous combination of local fields and not a normal polarity dipole field, i.e. the Gilsa is an excursion. Additional records of the Gilsa from geographically distributed sites are required to distinguish better between these two possibilities.

Whether the Gilsa is a very short polarity interval or an excusion, it seems to show the same style of partial directional recovery as recorded in the lower transition into the Cobb Mountain, suggesting a similarity in the processes governing the initiation of these features. However, whereas the transition back to reverse polarity in the Cobb Mountain shows a complementary set of features as in the initiating transition, the return to reverse polarity in the Gilsa is much abbreviated, as if the field never fully stabilized in the normal polarity state. Some evidence of apparent instability after a polarity transition is also seen within the full normal interval of the Cobb Mountain where inclinations become very shallow (75.60-75.65 mbsf).

The similarities in the timing and nature of the directional and intensity changes which are ob- 
served during full polarity transitions (Cobb Mountain) and possible excursions (Gilsa) may be reflecting similarities in the processes which caused these features. That is, the same triggering mechanism which causes an excursion may just as well cause an interval of very long polarity.

If this proves to be the case then it has important implications for studies which attempt to define characteristics of core processes using statistical studies of reversal frequency [36-39]. In addition to the most visible manifestation of the reversal process, full polarity intervals ranging in duration from several tens of thousands to millions of years, excursions or attempted reversals will need to be included in such analyses in order to obtain a more accurate statistical description of the reversal process.

\section{Acknowledgements}

We extend our thanks to A. Meyer, D. Schnieder and two anonymous reviewers for critically reading the manuscript and making several helpful suggestions. We are particularly grateful to Ellen Thomas, Paula Weiss, Bill Ruddiman, and Robb Kidd for their assistance in obtaining permission from the Deep Sea Drilling Project to sample these cores. The samples were supplied through the assistance of the Deep Sea Drilling Project. This work was supported by NSF grant OCE8300356. Lamont-Doherty Geological, Observatory Contribution Number 4060. Ocean Drilling Program Contribution Number ODP/P-87/116.

\section{References}

1 J.A. Jacobs, Reversals of the Earth's magnetic field, pp. 86-116, Adam Hilger Led., London, 1984.

2 B.M. Clement and D.V. Kent, A detailed record of the lower Jaramillo polarity transition from a southern hemisphere deep-sea sediment core, J. Geophys. Res. 89, 1049-1058, 1984

3 B.M. Clement and D.V. Kent, A comparison of two sequential geomagnetic polarity transitions (upper Olduvai and lower Jaramillo) from the southern hemisphere, Phys. Earth Planet. Inter. 39, 301-313, 1985.

4 R. Kidd, W.F. Ruddiman et al., Initial Reports DSDP 94, in press, U.S. Government Printing Office, Washington, D.C., 1986.

5 B.M. Clement and F. Robinson, Magnetostratigraphy of Leg 94 sediments, in: R. Kidd, W. Ruddiman et al., Initial Reports DSDP 94, in press, U.S. Government Printing Office, Washington, D.C., 1986.
6 W.A. Berggren, D.V. Kent, J.J. Flynn and J.A. Van Couvering, Cenozoic Geochronology, Geol. Soc. Am. Bull. 96, 1407-1418, 1985.

7 F.H. Chamalaun and I. McDougall, Dating geomagnetic polarity epochs in Reunion, Nature 210, 1212-1214, 1966.

8 E.A. Mankinen and G.B. Dalrymple, Revised geomagnetic polarity timescale for the interval 0-5 m.y. B.P., J. Geophys. Res. 84, 615-626, 1979.

9 E.A. Mankinen, J.M. Donnelly and C.S. Gromme, Geomagnetic polarity event recorded at $1.1 \mathrm{~m} . \mathrm{y}$. B.P. on Cobb Mountain, Clear Lake volcanic field, California, Geology 6 , 653-656, 1978.

10 N. Kawai, Paleomagnetic study of deep-sea sediments from the Melanesia Basin, J. Geomagn. Geoelectr. 29, 211-223, 1977.

11 D. Ninkovitch, N.D. Opdyke, B.C. Heezen and J.H. Foster, Paleomagnetic stratigraphy, rates of deposition, and tephrachronology in North Pacific deep-sea sediments, Earth Planet. Sci. Lett. 1, 476-492, 1966.

12 T. Sueshi, T. Sato, N. Kawai and K. Kobayoshi, Short geomagnetic polarity episodes in the Matuyama epoch, Phys. Earth Planet. Inter. 19, 1-11, 1979.

13 D.V. Kent, Post-depositional remanent magnetization in a deep-sea sediment core, Nature 246, 32-34, 1973.

14 D.V. Kent and D.J. Spariosu, Magnetostratigraphy of Caribbean Site 502 hydraulic piston cores, in: Prell et al., Initial Reports DSDP 68, 419-433, U.S. Government Printing Office, Washington, D.C.

15 D.K. Rea and R.J. Blakely, Short wavelength magnetic anomalies in a region of rapid seafloor spreading, Nature $255,126-128,1975$.

16 L. Tauxe, N.D. Opdyke, G. Pasini and C. Elmi, Age of the Plio-Pleistocene boundary in the Vrica section, southern Italy, Nature 304, 125-129, 1983.

17 F. Theyer, D. Burbank, S.P. Lund and J. McRaney, High resolution magnetic field transitions and related secular variation from Matuyama-aged sediments in Kashmir, India (abstract), EOS 66, 872, 1985.

18 N.D. Watkins, L. Kristjansson and I. McDougall, A detailed paleomagnetic survey of the type location for the geomagnetic polarity event, Earth Planet. Sci. Lett. 27, $436-444,1975$.

19 C.S. Gromme and R.L. Hay, Geomagnetic polarity epochs: Age and duration of the Olduvai normal polarity event, Earth Planet. Sci Lett. 10, 179-185, 1971.

20 B.M. Clement and D.V. Kent, Geomagnetic polarity transition records from five hydraulic piston core sites in the North Atlantic, in: R. Kidd, W. Ruddiman et al., Initial Reports DSDP 94, in press, U.S. Government Printing Office, Washington, D.C., 1986.

21 S. Levi and S.K. Banerjee, On the possibility of obtaining relative paleointensities from lake sediments, Earth Planet. Sci. Lett. 29, 219-271, 1979.

22 J.W. King, S.K. Banerjee and J. Marvin, A new rock magnetic method approach to selecting sediments for geomagnetic paleointensity studies: application to paleointensity for the last 4000 years, J. Geophys. Res. 88, 5911-5921, 1983.

23 E. Irving and A. Major, Post-depositional detrital remanent magnetization in a synthetic sediment, Sedimentology 3; 135-143. 1964. 
24 D.V. Kent, Post-depositional remanent magnetization in a deep-sea sediment core, Nature 246, 32-34, 1973.

25 E.A. Mankinen, M. Prévot, C.S. Grommé and R.S. Coe, The Steen's Mountain geomagnetic polarity transition, I. Directional history, duration of episodes and rock magnetism, J. Geophys. Res. 90, 10379-10417, 1985.

26 M. Prévot, E.A. Mankinen, R.S. Coe and C.S. Grommé, The Steen's Mountain geomagnetic polarity transition, II. Field Intensity variations and discussions of reversal models, J. Geophys. Res. 90, 10418-10448, 1985.

27 J.-P. Valet, C. Laj and P. Tucholka, Volcanic record of a reversal, Nature 316, 217-218, 1985.

28 K.A. Hoffman, Polarity transition records and the geomagnetic dynamo, Science 196, 1329-1332, 1977.

29 I. Williams and M. Fuller, Zonal harmonic models of reversal transition fields, J. Geophys. Res. 86, 11657-11665, 1981.

30 R.S. Coe, C.S. Grommé and E.A. Mankinen, Geomagnetic paleointensities from excursion sequences in lavas in Oahu, Hawaii, J. Geophys. Res. 89, 1059-1069, 1984.

31 K.A. Hoffman, Paleomagnetic excursions, aborted reversals and transitional fields, Nature 294, 67-69, 1981.
32 M. Barbetti and M.W. McElhinny, Evidence of a geomagnetic excursion 30,000 yr B.P., Nature 239, 202, 1972.

$33 \mathrm{M}$. Barbetti, The Lake Mungo geomagnetic excursion, Philos. Trans. R. Soc. London, Ser. A 281, 515, 1976.

34 R.S. Coe, Source models to account for the Lake Mungo paleomagnetic excursion and their implications, Nature $269,49,1977$.

35 J.C. Liddicoat and R.S. Coe, Mono Lake geomagnetic excursions, J. Geophys. Res., 84, 261-271, 1979.

36 A. Cox. The frequency of geomagnetic reversals and the symmetry of the non-dipole field, Rev. Geophys. Space Phys. 13, 35, 1975.

37 W. Lowrie and D.V. Kent, Geomagnetic reversal frequency since the Late Cretaceous, Earth Planet. Sci. Lett. 62, 305, 1983.

38 P.L. McFadden and R. Merrill. Lower mantle convection and geomagnetism, J. Geophys. Res., 84, 615-626, 1979.

39 A. Mazaud, C. Laj, L. deSeeze and K. Verusob, Evidence for periodicity in the reversal frequency during the last 100 Ma, Nature 304, 328-329, 1983. 